\title{
EL FUNDAMENTO DE LOS DERECHOS FUNDAMENTALES
}

\author{
Francisco J. BASTIDA FREIJEDO \\ CATEDRÁTICO DE DERECHO CONSTITUCIONAL \\ UNIVERSIDAD DE OVIEDO
}

\author{
s u m a r i o
}

I. Derechos humanos y derechos fundamentales. II. Concepción normativa de la fundamentalidad de los derechos fundamentales. I. Fundamentalidad externa (metajurídica). 2. Fundamentalidad interna (jurídica). III. Fundamentalidad de los derechos y sistema constitucional democrático. I. La selección de expectativas individuales y sociales por el constituyente y su transformación en derechos fundamentales. 2. Derechos fundamentales y organización jurídica de la democracia. IV. Los derechos fundamentales en la Constitución española. I. Dignidad humana y derechos fundamentales. Su función programadora en una constitución democrática. 2. El carácter fundamental de los derechos fundamentales y su manifestación en la Constitución española.

\section{Derechos humanos y derechos fundamentales.}

El estudio de los derechos fundamentales tiene como referencia ineludible los derechos humanos, aunque conviene dejar claro que unos y otros no son exactamente lo mismo. Desde siempre el ser humano ha buscado la manera de resistirse al poder de dominación y a lo largo de la historia ha ido creando fórmulas filosófico-jurídicas para frenar ese poder. De un lado, ideando principios de fundamentación, organización y modos de ejercicio del poder que sirvieran a esa finalidad limitadora; de otro, afirmando espacios de libertad y medios de reacción jurídicos frente a las injerencias del poder. Antes que en la antigua Grecia, en China se hablaba ya del «gobierno de las leyes frente al gobierno de los hombres» como forma de organizar el poder en garantía de los gobernados, y Confucio escribía sobre la dignidad del individuo y su respeto como deber del buen gobierno. Sin

* Este artículo corresponde al texto entregado como lección inaugural en la celebración de San Raimundo de Peñafort en la Facultad de Derecho de la Universidad de Zaragoza el día 2i de enero de 2005. Agradezco al decano D. José $\mathrm{M}^{\mathrm{a}}$ Gimeno y a su equipo la deferencia que tuvieron conmigo al concederme el honor de impartir dicha lección en día tan señalado. 
embargo, la idea de derechos humanos tal cual la conocemos hoy es relativamente reciente y se ubica en el pensamiento liberal revolucionario de finales del siglo XVIII.

Se pueden sintetizar en tres los modelos históricos de fundamentación de los derechos, aunque en puridad sólo el modelo iusracionalista (iusnaturalista) y el modelo positivista tienen un engarce inmediato. En ambos el punto filosófico de partida es el ser humano a secas, como sujeto libre e igual a los demás seres humanos. En el modelo de fundamentación historicista, si bien hay reconocimiento de derechos, su titular no es el hombre, el ser humano, sino unos individuos integrados en un estatus determinado (pertenencia a una gens o grupos sociales concretos, a un estamento, a un pueblo, etc.). En la antigua Grecia o en la Roma clásica -y los mismo se podría decir del pensamiento clásico oriental- el «hombre libre» no era el «hombre libre» del iusracionalismo plasmado en la Declaración francesa de Derechos del Hombre y del Ciudadano, de I789 (DDHC) o, unos pocos años antes, en la Declaración de Derechos de Virginia, de 1776 . En aquella lejana época el acento se ponía -como hacía Aristóteles- en la «naturaleza libre» como estatus atribuido a determinados sujetos, de manera que en la sociedad antigua convivían hombres libres con individuos sometidos a esclavitud o a una situación de semilibertad. Sin embargo, en la filosofía iusracionalista el acento se pone en el «hombre» en cuanto individuo de la especie humana. El estatus jurídico lo marca la propia condición humana, no la situación de libertad. Ésta es una circunstancia inherente y consubstancial a esa condición. De ahí la pretensión de universalidad de las declaraciones de derechos humanos. (Debe señalarse, no obstante, que en las realizaciones prácticas de la filosofía iusracionalista, casi nunca se mantuvo esta idea abstracta del ser humano como sujeto igual en derechos. La condición de mujer, de menor de edad o de pertenencia a otra raza fue una circunstancia de exclusión o aminoración de derechos, pese a la proclamación oficial de los derechos como «de los seres humanos». La propia distinción entre nacional y extranjero, casi irrelevante en la DDHC, se transformó con posterioridad en una separación radical en el acceso a la titularidad de algunos derechos fundamentales. Sólo el constitucionalismo democrático más reciente ha progresado -aunque no plenamente- en la dirección del reconocimiento jurídico del ser humano como ciudadano, bastando para ello su residencia habitual en el país al margen de cuál sea su nacionalidad de origen.

La idea básica del hombre sujeto y no objeto, del ser humano que por el hecho de nacer es portador de derechos inalienables e inviolables, se sintetiza en el concepto de dignidad humana, como valor consustancial a la persona, del que Kant ha hecho una de las más vigorosas teorizaciones. Las constituciones modernas son deudoras de esas declaraciones de derechos, integradas de una $u$ otra forma en su texto. No obstante, como al principio se adelantaba, no cabe identificar sin más derechos humanos y derechos fundamentales, porque el iusracionalismo y el positivismo, aun pudiendo coincidir en una idea común, (el individuo y su dignidad), son modelos que se construyen de manera muy diferente.

Puede decirse en una primera aproximación y en términos harto generales que el modelo positivista transforma los derechos humanos en derechos fundamentales. Los incorpora como un elemento esencial del sistema jurídico, que los reconoce y garantiza con la fuerza irresistible del único derecho válido, el derecho positivo, es decir, los respalda con el uso lícito de la fuerza física que ostenta en monopolio el Estado. Reclamar un derecho fundamental no consistirá en apelar sin más al respeto a un derecho natural de la persona. La apelación no tendrá virtualidad ante los poderes públicos si ese derecho no está previamente positivado, o sea, incorporado y garantizado como derecho positivo, único alegable ante los tribunales. De ahí que la declaraciones de derechos, hechas inicialmente al margen de las constituciones, aparezcan hoy en día integradas de una $\mathfrak{u}$ otra manera en ellas, ya como adhesión a su texto (Preámbulo de la Constitución Francesa de I958), ya como elenco de derechos fundamentales explícitamente reconocidos (la mayoría de las 
constituciones, incluida la nuestra, Caps. I y II del Título I CE), ya como instrumento para la interpretación de éstos (art. I0.2 CE).

\section{Concepción normativa de la fundamentalidad de los derechos fundamentales.}

Las constituciones utilizan una terminología diversa para referirse al reconocimiento de derechos: libertades públicas, libertades civiles, derechos y libertades, derechos fundamentales, etc. Incluso la CE emplea diferentes denominaciones y no siempre con el debido rigor, pero su Título I, el que da cobertura a esas diversas denominaciones, lleva el significativo rótulo «De los derechos y deberes fundamentales», siguiendo en este caso la estela marcada por la Ley Fundamental de Bonn (LFB). La expresión «derechos fundamentales» tiene la virtud de plantear dos preguntas claves: ¿hay derechos constitucionales no fundamentales?, ¿Cuál es el sentido de su fundamentalidad? Y estas son preguntas, que sirven para cualquier Constitución al margen de cuál sea la terminología usada en ella, exponen un asunto de capital importancia no sólo para la teoría de los derechos fundamentales, sino también para la teoría de la Constitución.

I. Fundamentalidad externa (metajurídica).

El constitucionalismo hunde sus raíces en el modelo iusracionalista, aunque progresivamente fue afirmando su sentido plenamente positivo al formalizarse en un Estado constitucional. Se acabó traduciendo en términos de derecho positivo lo que originariamente se entendía como derecho natural, previo al Estado y condición para la existencia de una Constitución. Ello significa que la formación de los derechos fundamentales, como la formación del concepto de Constitución, no responde desde su inicio a un modelo propiamente positivista.

En efecto, la evolución entraña una mixtura de modelos, iusracionalista y positivista. A lo largo de los siglos XIX y XX el sistema jurídico-constitucional se fue haciendo más autorreferencial (validez autónoma del derecho positivo, al margen de si su contenido coincide o no con los postulados de un supuesto derecho natural) y se dotó de mayor positividad (capacidad jurídica para regular cualquier materia sin condicionamientos externos, iusracionales o de otro tipo). Pero este proceso fue gradual, sobre todo en Europa, y no siempre sostenido en una misma dirección. La crítica contra el positivismo jurídico en los años 30 del siglo XX se tradujo en parte en una vuelta al iusracionalismo, a la idea de una suprapositividad que condiciona la positividad del ordenamiento constitucional. La LFB y su interpretación por el Tribunal Constitucional Federal Alemán (TCFA) reflejan esa tendencia. Para Benda «los inviolables e inalienables derechos humanos no han sido creados por la $L F B$, sino que ésta los contempla como parte integrante de un ordenamiento jurídico preexistente $y$ suprapositivo. ... se trata de proteger la dignidad como derecho originario de todo ser humano».

Esta concepción es, sin embargo, la propia del Estado liberal de derecho del siglo XIX y la que da vida a la DDHC. El Estado liberal se caracteriza por la radical separación entre Estado y Sociedad. La Constitución aparece como una norma que materializa el contrato social, en virtud del cual los individuos, libres e iguales por naturaleza (relación horizontal), se asocian en una sociedad civil. El poder público (Estado) creado por ese contrato sujeta a los individuos (relación vertical) al objeto de organizar la convivencia social en una situación de libertad en la mayor medida posible. En un planteamiento tal el poder 
no puede ser absoluto, lo cual requiere diferenciar entre el poder constituyente y los poderes constituidos, y éstos, a su vez, deben estar separados entre sí (legislativo, ejecutivo y judicial). Esta limitación estructural y formal del poder se superpone a la limitación sustancial que deriva de la idea de que hay unos derechos naturales del individuo que, como tales, preexisten al Estado. Son derechos que están en la exclusiva esfera de la sociedad y en ella se hace una proclamación solemne de los mismos. En su seno se declaran los derechos inherentes a los seres humanos. El Estado liberal los reconoce en su Constitución como anteriores a él, y la función para la que es creado es justamente la de respetar su existencia, y darles amparo legal. Todo ello explica por qué el art. i6 de la DDHC establece un concepto material de Constitución basado en esos dos elementos: «Toda sociedad en la que la garantía de los derechos no está asegurada ni la separación de poderes establecida, no tiene Constitución».

En el Estado liberal de derecho la diferencia entre un derecho fundamental y un derecho simplemente constitucional reside precisamente en esta posición externa y previa de los derechos fundamentales. Subraya C. Schmitt que «en el Estado burgués (liberal) de derecho son derechos fundamentales sólo aquellos que pueden valer como anteriores y superiores al Estado, aquellos que el Estado, no es que otorgue con arreglo a las leyes, sino que reconoce y protege como dados antes que él, y en los que sólo cabe penetrar en una cuantía mensurable en principio y sólo dentro de un procedimiento regulado».

De aquí se desprenden varias conclusiones de singular importancia para entender la concepción liberal y su influencia, todavía presente, en la caracterización doctrinal de los derechos fundamentales:

a) La fundamentalidad de los derechos tiene un sentido que podría calificarse de antropocéntrico. Serán «fundamentales» los derechos que se entiendan como más básicos o esenciales del ser humano. Aquellos que se consideren inherentes al desarrollo de su personalidad.

b) La fundamentalidad de los derechos emana del ser del individuo, del ser humano, no del deber ser de la norma constitucional. La fundamentalidad de los derechos fundamentales está desvinculada del derecho positivo. No tiene que ver con la posición de supremacía de la Constitución, como norma fundamentadora del ordenamiento jurídico. Aunque la Constitución no los reconozca, existen. Para la doctrina liberal (art. I6 DDHC), si ese reconocimiento no se da, la que no existirá como tal será la Constitución (concepto material de Constitución), aunque se le llame así a la norma fundamental del Estado.

c) En la tajante separación entre Estado y Sociedad, los derechos fundamentales están radicados exclusivamente en la esfera social. Se conciben como derechos absolutos, en el sentido de espacios de una libertad en principio ilimitada. Ninguna norma positiva los crea y sólo la ley -de manera excepcional y si está constitucionalmente habilitada para ellolos limita. De ahí su calificación de derechos «inalienables, inviolables, imprescriptibles»e incluso «sagrados» (Preámbulo de la DDHC).

d) Al tratarse de una fundamentalidad derivada del nexo de las libertades con la esfera individual y, todo lo más, social (entre individuos), los derechos fundamentales son libertades privadas, sin dimensión política de relación con el poder público. Los llamados derechos de participación (sufragio) o de prestación no son fundamentales. La única relación con el poder es de defensa frente a injerencias que no tengan apoyo legal. Por eso en la doctrina liberal los derechos fundamentales reciben el nombre de libertades negativas, libertades civiles o derechos de libertad y se articulan jurídicamente como derechos reaccionales o de defensa. 
e) La positividad de los derechos fundamentales queda circunscrita al campo de la limitación de los derechos, a la forma que ha de tener la norma limitadora (ley general) y a los procedimientos reaccionales de tutela frente a aquellas injerencias. Pero es una positividad debilitada, restringida, porque el sistema constitucional liberal renuncia a fundamentar jurídicamente los derechos. La validez de éstos, su existencia jurídica, queda situada fuera y por encima de la Constitución.

f) La merma de positividad $-y$, por tanto, de capacidad jurídica para configurar los derechos fundamentales desde y por la Constitución- mantiene a estos derechos en la esfera social y los preserva de injerencias estatales. En principio esto parece favorable a los derechos, pero es también un freno e incluso una barrera a la posibilidad de intervenir desde la esfera jurídico-estatal para garantizar los derechos fundamentales; por ejemplo, cuando los obstáculos que impidan el ejercicio de esas libertades se generen en el seno de la propia sociedad, como consecuencias de las relaciones sociales.

2. Fundamentalidad interna (jurídica).

Las constituciones democráticas son históricamente una evolución de las constituciones liberales y, en apariencia, los derechos fundamentales contenidos en ellas son básicamente los mismos. Sin embargo, las normas de derecho fundamental que subyacen bajo un enunciado similar pueden ser muy diferentes y, sobre todo $-\mathrm{y}$ es lo que ahora importa- tienen un fundamento jurídico completamente distinto, porque, en general, las constituciones democráticas se enmarcan en una concepción positivista del ordenamiento jurídica en el que la Constitución es la norma jurídica suprema y, como tal, fuente primaria u originaria de producción de las demás normas del ordenamiento.

A pesar de este cambio radical, gran parte de la doctrina científica sigue anclada en la fundamentación antropocéntrica y iusracional de los derechos humanos; en el fondo, no se ha asimilado plenamente la idea de que la positivación constitucional de los derechos les priva de su supuesto carácter preestatal, de su pretendida condición natural de derechos inviolables, inalienables e imprescriptibles. Como decía Jellinek, no todos los que niegan el derecho natural están libres de sus cadenas.

Este erróneo punto de partida dificulta el encontrar respuestas coherentes en asuntos relativos a la titularidad de derechos fundamentales (nasciturus, personas fallecidas, personas jurídicas, minorías sociales, etc.), o a su eficacia (nuevas posiciones de los poderes públicos ante los derechos, eficacia horizontal de éstos, etc.), por no hablar de su estructura, objeto y contenido.

Cuando la Constitución se erige en norma jurídica suprema y fuente única de la validez o de la aplicabilidad de todas las demás normas que componen el ordenamiento jurídico, el sistema constitucional se hace autónomo y organiza internamente su validez. Por tanto, si la Constitución reconoce derechos fundamentales no puede ser como aceptación de una legalidad iusracional previa, externa e intangible. Una Constitución no lo es por contener una declaración de derechos, como pretendía el art. I6 de la DDHC. Lo es por su más alta posición jurídica respecto del resto de normas del ordenamiento, o sea por su carácter de norma fundamentadora de todas las demás. Si esto es cierto, la explicación de por qué unos derechos son «fundamentales» es sencilla. Lo son, porque y en la medida en que participan de esa posición de supremacía que tiene la Constitución en la que están insertos; por el contrario, no son calificables como fundamentales si carecen de ese rango o quedan desprovistos de él y entran en el campo de la entera y libre decisión del legislador. El ser unos derechos que puedan considerarse inherentes a las personas no es la causa de su deber ser como normas iusfundamentales. Puede que ese sea el «motivo político» que 
impulsa al constituyente a incluirlos en la norma fundamental del ordenamiento, pero la «causa jurídica» de su validez como derechos fundamentales está en la citada posición normativa suprema, que es la que los hace inviolables frente a cualquiera que no sea el órgano de reforma constitucional (ausencia de impunidad frente a la infracción). El derecho a la vida (art. I5 CE) es jurídicamente un derecho fundamental, porque la CE así lo dispone, es decir, porque establece una pretensión subjetiva de eficacia directa y el legislador no la puede suprimir, y sólo la puede regular en los términos y con la condiciones predeterminadas por la Constitución; su validez jurídica no deriva del hecho de que la vida sea esencial para el ser humano; este puede ser -como se dijo antes- el motivo que lleva al constituyente a darle relevancia jurídica a tal pretensión. Por la misma razón pero en sentido contrario, el derecho a la protección de la salud (art. 43.I CE) no es un derecho fundamental, a pesar de que nadie dudará de que es fundamental para la persona tener garantizada la protección de la salud. Simplemente no es derecho fundamental porque la Constitución no lo sitúa en esa posición normativa suprema; su configuración jurídica la encomienda por completo al legislador y el individuo sólo podrá alegar ese derecho en los términos dispuestos en la ley (art. 53.3 CE).

Las dos características que tipifican a un derecho fundamental derivan de la doble dimensión de la Constitución en cuanto fuente jurídica: como fuente sobre las demás fuentes y como fuente suprema de eficacia directa. En la primera vertiente, la Constitución regula la producción de normas y sus destinatarios son el legislador y los demás poderes públicos, a los que les está vedada la libre disposición sobre los derechos constitucionalmente establecidos. En la otra vertiente, la Constitución actúa como fuente que crea directamente relaciones jurídicas. Dotada de eficacia inmediata, su destinatario puede ser cualquiera y su objeto cualquier ámbito vital. La doble participación en la condición de la Constitución como fuente hace que los derechos fundamentales sean inatacables y de eficacia potencialmente inmediata.

La primera caracterización (la indisponibilidad de los derechos fundamentales por el legislador) es quizá la más perceptible, sobre todo en los derechos que precisan para su pleno ejercicio de una previa interposición del legislador. Sin embargo, un entendimiento más hondo de la fundamentalidad de los derechos permite concluir que ésta consiste primariamente en la eficacia directa de tales derechos, o sea, en su potencial disponibilidad inmediata por sus titulares. La posición del legislador queda predeterminada así por esta potencial eficacia inmediata de las normas iusfundamentales. Es lógico que así sea, porque si un sistema jurídico sitúa en el núcleo de su estructura y de su funcionamiento la atribución de derechos a los individuos, procurará dotarlos de la mayor eficacia posible, sin interferencias de los poderes públicos o de otros sujetos; de su garantía y eficacia dependerá el funcionamiento del sistema constitucional. Por tanto, el legislador no podrá disponer de los derechos para negarlos. Es posible que algunos derechos fundamentales no los pueda ejercer su titular sin una previa intermediación del legislador, (por ejemplo, el derecho a la tutela judicial efectiva o el derecho de sufragio), pero ello no impide afirmar que comportan una disponibilidad potencialmente inmediata, y que se concreta en la posibilidad de exigir que los poderes públicos arbitren la organización y los procedimientos necesarios para dar efectividad esos derechos. La omisión o desatención de esta obligada intervención del legislador hará emerger la eficacia directa de la norma iusfundamental, aunque sea en su contenido mínimo o esencial.

En suma, un derecho fundamental es ante todo un derecho subjetivo, es decir, un apoderamiento jurídico (contenido del derecho) que la Constitución, atribuye a un sujeto para que pueda defender, asegurar o ejercer determinadas expectativas (objeto del derecho). Ese apoderamiento consistirá en la posibilidad de, con la fuerza normativa de la Constitución, exigir a un tercero, sea un poder público o un particular, el cumplimiento de un deber; (de actuar, en unos casos, o de abstenerse de actuar, en otros). Sólo son fundamentales los derechos que participan de la fundamentalidad de la norma fundamental 
del ordenamiento jurídico, la Constitución, lo cual significa que ésta, como fuente jurídica directamente aplicable, establece esos derechos y los dota de una disponibilidad por su titular potencialmente inmediata, $y$, como fuente de las demás fuentes del ordenamiento, preserva a los derechos fundamentales de su alteración o vulneración por normas infraconstitucionales (y en algunos casos incluso constitucionales) y los hace indisponibles por el legislador (e incluso por el órgano de reforma constitucional).

Desde esta perspectiva estrictamente jurídico-positiva, los derechos fundamentales tienen este carácter con independencia de quién sea su titular y de cuál sea la estructura en la que estén articulados. Como ya queda dicho, no cabe aquí una fundamentación antropocéntrica de los derechos fundamentales. Si la condición jurídica de fundamentales no la reciben tales derechos por ser inherentes a la persona, no es consustancial a esos derechos que su titular sea exclusivamente el ser humano. Puede que no todas las personas físicas sean titulares de esos derechos, y puede que el nasciturus, las personas fallecidas y las personas jurídicas, privadas e incluso públicas, sí lo sean. En teoría, podría atribuirse capacidad iusfundamental también a los animales. De igual modo, los derechos fundamentales no implican una determinada estructura normativa. Pueden ser derechos fundamentales tanto derechos de libertad o de defensa (derecho a la vida o al honor), como derechos con un alto contenido prestacional (derecho a la educación). Otro tanto cabe afirmar sobre la eficacia de tales derechos, que no sólo es frente al poder público, sino frente a todos, sean poder público (eficacia vertical) o particulares (eficacia horizontal). Los derechos fundamentales no son libertad natural retenida por el individuo frente al poder público, sino un haz de facultades de disposición atribuidas a sus titulares por la Constitución para hacer frente desde la supremacía constitucional a cualquier acción $u$ omisión ilegítima contra el disfrute del objeto del derecho, provenga de quien provenga.

\section{Fundamentalidad de los derechos y sistema constitucional democrático.}

I. La selección de expectativas individuales y sociales por el constituyente y su transformación en derechos fundamentales.

$\mathrm{Si}$ un ordenamiento jurídico no precisa para su existencia de derechos fundamentales y su norma suprema, la Constitución, no se define por el hecho de proclamar tales derechos sino por su posición jurídica suprema ¿por qué algunas Constituciones contienen un catálogo de derechos fundamentales, concebidos en el sentido exclusivamente jurídico dado aquí al concepto?. La explicación está en la selección de expectativas individuales y sociales hecha por el constituyente. Cuando éste establece derechos fundamentales es porque considera que para el funcionamiento del sistema jurídico que desea implantar es esencial dar la máxima protección jurídica a determinadas pretensiones y expectativas de autodisposición de los individuos e incluso de los grupos en las que éstos se organizan. Para ello las inserta en la norma más alta del ordenamiento jurídico y las regula como ámbitos jurídicos cuya existencia es indisponible por el legislador, lo que las hace jurídicamente fundamentales. Además, -y por esto son derechoslas articula jurídicamente no sólo como bienes constitucionalmente protegibles, sino también como apoderamientos a los sujetos de tales expectativas para que puedan hacer valer frente a todos esos ámbitos protegidos, cuando menos su núcleo esencial; se garantiza así una potencial disponibilidad inmediata de los derechos fundamentales por su titular. 
La selección y preferencia por el constituyente de unas expectativas individuales y sociales frente a otras tiene su reflejo jurídico no sólo en la determinación de cuáles quedan configuradas como derechos fundamentales, sino también en el distinto grado de protección normativa que la Constitución puede dispensar a estos derechos. En este sentido, dentro de los derechos fundamentales podría hablarse de una mayor o menor fundamentalidad de ellos, en función de ese grado de preservación normativa contemplado en la Constitución. Piénsese que no es lo mismo la posibilidad de regular el desarrollo de un derecho fundamental mediante una reserva de limitación (art. I6.I CE) que a través de una reserva de delimitación (art. 23.2 CE); En la primera la Constitución deja más margen de actuación al legislador porque le permite establecer límites que de otro modo no podría. La intensidad del carácter fundamental se acrecienta cuando las normas iusfundamentales impiden de plano al legislador especular con determinadas expectativas (prohibición de la pena de muerte en relación con el derecho a la vida, o prohibición de torturas y de penas o tratos inhumanos o degradantes en relación con el derecho a la integridad física y moral, art.I5 CE). Como recuerda el TC, «La distinción entre poder constituyente y poderes constituidos no opera tan sólo en el momento de establecerse la Constitución; la voluntad y racionalidad del poder constituyente objetivadas en la Constitución no sólo fundan en su origen sino que fundamentan permanentemente el orden jurídico y estatal y suponen un límite a la potestad del legislador» (STC $76 / 1983$ F.J. 4).

La fundamentalidad de algunos derechos se intensifica cuando su especial salvaguardia no es sólo respecto del legislador, sino también respecto del órgano de reforma constitucional, mediante la fijación de un procedimiento más agravado para modificar tales derechos (art. I68 CE) e incluso a través de cláusulas de intangibilidad que prohíben al poder de reforma constitucional su supresión (art. 79.3 LFB). (Obsérvese que se habla de mayor o menor fundamentalidad de los derechos en función de su de mayor o menor preservación normativa, lo cual no implica necesariamente una mayor o menor garantía jurisdiccional de los derechos. El que unos derechos fundamentales sean protegibles ante el TC mediante el recurso de amparo no los hace más fundamentales que otros que no cuentan con esta garantía adicional. Tampoco implica una jerarquización de los derechos fundamentales, porque todos son derechos de rango constitucional).

La fundamentalidad de los derechos tiene así, desde la perspectiva del constituyente (y del propio ordenamiento jurídico como sistema) una explicación funcional; ciertos derechos se articularán como fundamentales en el texto constitucional porque las pretensiones y expectativas que forman su objeto se estiman claves para la organización y el funcionamiento del sistema constitucional que se trata de establecer. Depende de cuál sea la sociedad que se piensa ordenar jurídicamente, la Constitución articulará como fundamentales unos u otros derechos, los asignará a unos o a otros sujetos y configurará su estructura iusfundamental de uno $u$ otro modo. Por ejemplo, un sistema jurídico socialista no regulará como fundamentales los mismos derechos que un sistema liberal-democrático. Un sistema constitucional democrático considerará el sufragio universal como uno de sus derechos más fundamentales; un sistema liberal, no. Éste, en cambio, establecerá la propiedad privada como un derecho fundamental con una estructura de derecho subjetivo, mientras que una Constitución democrática posiblemente organice la propiedad como un derecho fundamental desde la perspectiva de una garantía institucional y una Constitución socialista no concebirá ese derecho como fundamental e incluso impedirá que la expectativa de propiedad privada de los medios de producción tenga cabida en el ordenamiento jurídico. 
2. Derechos fundamentales y organización jurídica de la democracia.

Una Constitución democrática establece derechos y libertades individuales y los regula en normas iusfundamentales porque considera imprescindible que la expectativa de individuos libres e iguales, con posibilidad de autonomía individual y colectiva, quede garantizada jurídicamente como núcleo del sistema jurídico que implanta, o sea, como normas de reconocimiento del sistema como «democrático». Sin ellos no podría identificarse una Constitución y un sistema jurídico como democráticos, por más proclamas (hueras) de democracia que hubiese en sus enunciados.

Lo dicho no significa que sólo pueda calificarse de democrática la Constitución que incorpore expresamente un catálogo de derechos fundamentales. Esto sería tanto como caer en el puro nominalismo de entender que, por contener sin más el enunciado de un elenco de derechos, una Constitución es democrática y que no lo es si sólo consagra la democracia como uno de sus principios básicos, sin una mención explícita de concretos derechos. Si el principio democrático no es dentro de esa Constitución un flatus vocis, los derechos fundamentales existirán normativamente en abstracto, como contenido jurídico imprescindible de dicho principio constitucional. El problema es que su concreción quedaría diferida a una incierta interpretación deductiva de cuáles son esos derechos, su ámbito y su contenido. De ahí que en general el constituyente democrático, además de proclamar en la norma suprema los principios y valores superiores que informan el ordenamiento jurídico, establezca expresamente un catálogo de derechos fundamentales. De este modo, no sólo aleja aquella incertidumbre sobre cuáles son estos derechos, sino que materializa también cuál es el contenido iusfundamental que ha de atribuirse a los principios y valores constitucionales consagrados en la Constitución y, muy en especial, al principio democrático. Se crea así un efecto recíproco entre principio democrático y derechos. Los derechos fundamentales dan contenido a esos principios y valores y éstos, rellenados por aquéllos, ilustran el sentido de cada derecho en relación con el conjunto. Por tanto, los derechos fundamentales establecidos por la Constitución orientan la interpretación de los principios y valores constitucionales, y éstos, en cuanto abstracción de tales derechos, facilitan una interpretación sistemática y constitucionalmente adecuada de los derechos fundamentales en su relación con los demás derechos y bienes constitucionalmente protegidos.

Pudiera pensarse que un sistema democrático gozaría de mayor garantía si la protección de su núcleo esencial, los derechos fundamentales, no se confía a una norma positiva, creada por el hombre, por más supremacía que tenga dentro del ordenamiento jurídico. Un renaciente iusracionalismo estimará más adecuado situar ese núcleo en una ley natural inmutable, indisponible no sólo para el legislador, sino también para el constituyente. Sin embargo, los propios principios del sistema democrático conducen a que su garantía jurídica se organice en un sistema jurídico autorreferencial y plenamente positivo, sin lastres iusnaturalistas.

En efecto, la democracia como mejor se articula jurídicamente es a través de un sistema constitucional autorreferencial (la Constitución como norma jurídica suprema y parámetro de reconocimiento de todas las demás normas) y dotado de positividad (sin límites materiales a su capacidad reguladora), es decir, como un sistema jurídico soberano. La razón estriba en que la democracia concentra en su esencia esas mismas cualidades que el ordenamiento jurídico precisa para ser soberano. La democracia implica, de un lado, autorreferencialidad individual (autonomía o libertad de seres iguales), y colectiva, (identificación o correspondencia entre gobernantes y gobernados) y, de otro, positividad (libertad para decidir; todo es posible y mudable si se decide por el procedimiento establecido). 
La organización en sociedad de esa autonomía individual y colectiva ha de hacerse a través de un sistema jurídico en el que una y otra estén garantizadas de manera incondicionada. Ello significa trasladar por completo dicho principio filosófico-político de autonomía al sistema jurídico, o sea, traducirlo en términos jurídicos, para que informen y rellenen de contenido su estructura y su funcionamiento, lo cual necesariamente conduce por lógica a que el ordenamiento jurídico se articule como sistema autorreferencial, sin dependencias jurídicas externas. De lo contrario no podría darse esa garantía incondicionada.

El mito de la soberanía popular, que late tras la idea de democracia, su fuerza legitimadora, radica precisamente en la idea reflexiva, de autogobierno individual (libertad) y colectivo (participación en las decisiones que afectan a todos), que pretende poner de manifiesto. El mito es pernicioso en cuanto esa idea no aparezca integrada en el sistema jurídico, es decir, en cuanto la autorreferencialidad de la soberanía popular no se transmita por completo al ordenamiento para organizar su estructura y funcionamiento de manera democrática. El Estado de derecho y más aún el Estado democrático de derecho, nacen precisamente para neutralizar la hipótesis de un poder soberano cuya omnipotencia se impone sin sujeción a regla alguna. Fuera de esa incardinación en una estructura democrática del ordenamiento, la idea de soberanía popular puede ser un peligro, porque pierde de vista el punto de partida filosófico que le da vida, el individuo y su libertad, igual a la de los demás. En nombre del pueblo soberano podrían quedar sacrificadas la libertad e igualdad individuales.

La doctrina liberal -en la que se basa también una determinada concepción democrática- argumenta que este mismo punto de partida entraña la idea de que los individuos no renuncian a todos sus derechos naturales al constituirse la sociedad civil. No se produciría aquella transmisión plena de poder y, por tanto, el sistema jurídico debería ser heterorreferencial, dependiente en última instancia del derecho natural que supuestamente da validez a esos derechos retenidos. Es necesario -se afirma- separar la legalidad positiva de la legitimidad natural (de un pueblo o nación preexistente). Se trataría, así, de contrarrestar los peligros de un absolutismo legalista e impedir la cautividad del poder originario del pueblo. La conclusión a la que se llega es que no puede convertirse al ordenamiento jurídico positivo en una normatividad incondicionada.

Sin embargo, este planteamiento no es coherente con la esencia de la democracia como principio informador de un sistema constitucional. En una democracia la idea de pueblo soberano no puede tener como función privar al ordenamiento jurídico positivo de su carácter incondicionado. En la positividad del derecho está la fuerza creadora capaz de establecer las condiciones jurídicas para la realización de ese ideal de autogobierno de una sociedad de individuos libres e iguales. Limitar externamente esa capacidad en nombre de dicho ideal es un contrasentido. La solución no está en frenar la positividad del ordenamiento jurídico resucitando de uno $u$ otro modo el derecho natural, sino en orientarla organizando la estructura del ordenamiento de tal modo que aquel ideal sea realizable.

En eso consiste precisamente el sistema constitucional democrático. Asigna al absoluto político que entraña la idea de una sociedad de individuos libres e iguales (base de la idea de soberanía popular) la función de programar el ordenamiento jurídico para garantizar la autonomía individual y colectiva. La concreción constitucional de esa función son los derechos fundamentales, y su corolario organizativo, el Estado democrático y social derecho. Por eso, como ya se dijo antes, los derechos fundamentales son derechos; porque articulan jurídicamente en su objeto y contenido esas expectativas de autonomía individual y colectiva, y son fundamentales, porque, dado el carácter esencial que tienen tales expectativas para una organización democrática de la sociedad, los derechos en que se traducen los sitúa la Constitución en una posición de supremacía jurídica. En el Estado 
constitucional democrático no hay soberano; soberana es la Constitución (No hay otra norma por encima de ella y todas las demás le están subordinadas, STC 84/1989, F.J. 49. La idea nuclear de la soberanía popular se traduce normativamente en el principio constitucional democrático y se concreta sobre todo en los derechos fundamentales que, en cuanto partícipes de esa supremacía jurídica de la Constitución, pero sólo en este sentido, podrían calificarse como fragmentos de soberanía.

En suma, si el único derecho valido es el derecho positivo, el sistema jurídico se configura como un sistema con identidad propia (soberanía del ordenamiento jurídico a través de su autorreferencialidad y positividad). Su característica es la regulación del uso irresistible de la fuerza física para estabilizar determinadas expectativas sociales. La forma de impedir que ese uso se vuelva contra los individuos no es apelando a un inexistente derecho natural de resistencia a la opresión, tal como proclamaba el art. 2 de la DDHC. Por el contrario, se consigue si se hace de la Constitución la norma jurídica suprema, soberana, y si se convierte aquella idea primigenia de libertad e igualdad en contenido de pretensiones jurídicas garantizadas por la Constitución. En este sentido los derechos fundamentales, al participar de la máxima fuerza normativa de la Constitución, de su fuerza irresistible suprema, pueden ser definidos como derechos resistentes frente a todos; resistentes también frente al ejercicio de supuestos «derechos naturales» y frente a voluntades colectivas preestatales (la supuesta «voluntad nacional» expresada fuera de los cauces constitucionales del poder de reforma constitucional).

\section{Los derechos fundamentales en la Constitución española.}

I. Dignidad humana y derechos fundamentales. Su función programadora en una constitución democrática.

Nuestro sistema constitucional responde a una concepción democrática que adopta como valores superiores «la libertad, la justicia, la igualdad y pluralismo político» (art. I.I CE). Este norte constitucional tiene su punto de partida en el postulado de que «la dignidad de la persona, los derechos inviolables que le son inherentes, el libre desarrollo de la personalidad, el respeto a la ley y a los derechos de los demás son fundamento del orden político y de la paz social» (art. IO.I CE). Esto no significa que la CE establezca un sistema jurídico heterorreferencial, dependiente de un derecho suprapositivo o de un orden político preexistente, tal como se interpreta la cláusula de intangibilidad de la dignidad humana reconocida en el art. I.I de la LFB. Al contrario, es la dignidad humana la que «fundamenta el orden político y la paz social». Su configuración jurídica se erige en pieza básica del ordenamiento constitucional para cimentar ese orden político y la paz social. El concepto constitucional de dignidad humana expresa el reconocimiento jurídico de la igualdad y libertad todos los seres humanos por el hecho de serlo, (STC 181/2000, F.J. 99, plasmadas en aquellos valores superiores del ordenamiento jurídico tal cual los establece el art. I.I CE y que se materializan en los derechos fundamentales del Título I.

Proyectada sobre los derechos individuales, la regla del art. Io.I C.E. implica que, en cuanto «valor espiritual y moral inherente a la persona» (STC 53/1985, fundamento jurídico $8^{\circ}$ ), la dignidad ha de permanecer inalterada cualquiera que sea la situación en que la persona se encuentre -también, qué duda cabe, durante el cumplimiento de una pena privativa de libertad (...)- constituyendo, en consecuencia, un minimun invulnerable que todo estatuto jurídico debe asegurar, de modo que, sean unas $u$ otras las limitaciones que se impongan en el disfrute de derechos individuales, no conlleven menosprecio para la estima que, en cuanto ser humano, 
merece la persona. Pero sólo en la medida en que tales derechos sean tutelables en amparo y únicamente con el fin de comprobar si se han respetado las exigencias que, no en abstracto, sino en el concreto ámbito de cada uno de aquellos, deriven de la dignidad de la persona, habrá de ser ésta tomada en consideración por este Tribunal como referente. No, en cambio, de modo autónomo para estimar o desestimar las pretensiones de amparo que ante él se deduzcan (STC 120/1990 F.J. 49).

Si la CE no estableciese explícitamente qué derechos o libertades son inherentes a la persona, qué derechos implica el reconocimiento constitucional de la dignidad humana, habría que deducirlos de esta referencia genérica del art. IO.I CE, lo cual crearía no pocas incertidumbres. Sin embargo, como el Título I concreta un catálogo de derechos, ha de entenderse que en él se hallan referenciados tales derechos y -como se acaba de ver en la STC 120/1990- «no en abstracto, sino en el concreto ámbito de cada uno de ellos». Se produce, así, una relación recíproca entre esos derechos y la dignidad humana reconocida en el art. IO.I CE. Ésta se irradia a los derechos fundamentales constitucionalmente reconocidos y que el intérprete de la CE estime inherentes a la persona, pero a su vez el concepto constitucional de dignidad queda circunscrito en la CE a los términos en los que dichos derechos están establecidos en su Titulo I.

Los derechos fundamentales forman el núcleo de la CE, son «los componentes estructurales básicos, tanto del conjunto del orden jurídico objetivo como de cada una de las ramas que lo integran en razón de que son la expresión jurídica de un sistema de valores, que, por decisión del constituyente ha de informar al conjunto de la organización jurídica y política» (STC 53/1985 F.J. $4^{\circ}$ ). Por tanto, condicionan y programan toda la estructura constitucional: la organización de España como Estado social y democrático de derecho (art. I.I), la existencia de un parlamento representativo, las Cortes Generales, como representantes del pueblo español (arts 66, 68.4 y 5 y 69.2 y 5), la regulación de un Poder judicial independiente (Título VI), y garante de los derechos (53.2 y II7.4) y de un Tribunal Constitucional como supremo intérprete de la Constitución y órgano extraordinario de amparo (Título IX), la delimitación de la potestad reglamentaria del Gobierno (art. 97) y de su intervención en la celebración de tratados internacionales (art. 94.I), la función de la Administración (art. I03) y de las Fuerzas y Cuerpos de seguridad del Estado (art. I04) las reservas de ley (art. 53.I) y de ley orgánica (art. 8I) . La limitación de la facultad legislativa del Gobierno, ya sea aprobando legislación de urgencia (86.I) o legislación delegada (art. 82.I), las obligaciones de los poderes públicos de promover las condiciones para que la libertad y la igualdad del individuo y de los grupos en que se integra sean reales y efectivas; (la de) remover los obstáculos que impidan o dificulten su plenitud y facilitar la participación de todos los ciudadanos en la vida política, económica, cultural y social. (art. 9.2) o la de inspirar su actuación en los principios rectores de la política social y económica (Cap. III del Título I), la distribución territorial del poder (arts. 8I, I39 y I49.I. ${ }^{a}$ ), la delimitación del ámbito de los estados de crisis y de la suspensión de derechos fundamentales (arts. 55 y гі6), y, en fin, la delimitación de las vías procedimentales de actuación del poder de reforma constitucional.(art. I68).

De esta función programadora de los derechos fundamentales en un ordenamiento constitucional democrático surge la dimensión objetiva de éstos (SSTC 25/1985 F.J. 5 , 249/1991, F.J. $4^{\circ}$ ). Los derechos fundamentales tienen un sentido propio expresado en su ámbito y contenido, pero también un sentido en su relación de conjunto con el sistema de derechos constitucionalmente establecido y que influye en la concreción de ese ámbito y contenido. Esto puede reforzar la fundamentalidad de los derechos en la medida en que se considera que también su dimensión objetiva queda amparada bajo la supremacía de la Constitución, pero puede debilitarla si la protección de la dimensión objetiva se interpreta como una habilitación al legislador para delimitar los derechos desdibujando los contornos de aquel sentido propio del derecho, su dimensión subjetiva, o para interponerse en el ejercicio del derecho y diferir su eficacia directa. 
2. El carácter fundamental de los derechos fundamentales y su manifestación en la Constitución española.

La explicación jurídica hasta aquí sostenida de en qué consiste la fundamentalidad de los derechos fundamentales no puede confundirse con una concepción puramente formalista o nominal de tales derechos. Estos no son fundamentales por el mero hecho de que así los califique la Constitución. El Título I de la CE se denomina «De los derechos $y$ deberes fundamentales», pero dentro de él conviven muy diferentes preceptos constitucionales y no todos contienen normas iusfundamentales. Dicho Título I no tiene una organización muy afortunada y el deseo del constituyente de hacer una amplia proclamación de derechos pudo más que el necesario rigor jurídico. La confusión es perceptible en el nombre de los cinco capítulos que componen ese Título; los términos «derechos» y «derechos fundamentales» se emplean sin un criterio definido: «I. De los españoles y los extranjeros». «II. Derechos y libertades», dividido en dos Secciones, «I ${ }^{a}$. De los derechos fundamentales y libertades públicas». « $2^{\mathrm{a}}$. De los derechos y deberes de los ciudadanos». «III. De los principios rectores de la política social y económica», que aparecen desgranados algunos de ellos como «derechos» (a la protección de la salud, a la cultura, al disfrute de un medio ambiente adecuado, a una vivienda digna). «IV. De las garantías de las libertades y derechos fundamentales». «V. De la suspensión de los derechos y libertades».

Esta falta de rigor repercute en la referencia que en otras partes de la CE se hace a los derechos fundamentales. Por ejemplo, la reserva de ley orgánica prevista en el art. 8I.I para el «desarrollo de los derechos fundamentales y libertades públicas» o la necesaria autorización de las Cortes para que el Estado se obligue por medio de tratados o convenios internaciones cuando éstos afecten «a los derechos y deberes fundamentales establecidos en el Título I». El TC ha intentado poner un poco de orden, pero acudiendo a un criterio nominalista que, si bien da certeza a la hora de deslindar la reserva de ley orgánica, no permite una definición coherente de qué es un derecho fundamental. Para el TC los derechos fundamentales y libertades públicas reservados a la ley orgánica son los que aparecen bajo la rúbrica de la Secc. ${ }^{\mathrm{a}}$, del Cap. II, del Tít. I CE «De los derechos fundamentales y libertades públicas», o sea, los reconocidos entre los arts. I5 y 29 CE (STC 76/1983, F.J. 2). El deseo de una interpretación restrictiva del ámbito de la ley orgánica no puede conducir a negar el carácter de derechos fundamentales a otros derechos del Título I, porque la fundamentalidad de los derechos no descansa en su ubicación formal dentro de la Constitución, sino en su configuración constitucional como normas de potencial autodisposición por el titular del derecho y, a la vez, de existencia indisponible por el legislador. En la CE no sólo se encuentran en tal situación los derechos comprendidos entre los arts. I5 al 29, sino también todos los del Título I, Capítulos I y II.

Por la misma razón no son derechos fundamentales los derechos del Capítulo III del Título I, a pesar de establecerse como «derechos». Hubiera sido un contrasentido que la CE proclamase como derecho fundamental el «derecho a disfrutar de una vivienda digna y adecuada» (art. 47) cuando lo que hace es remitir al legislador la competencia para definir el objeto, contenido y límites de ese derecho (art. 53.3). Esto no significa que el derecho a la vivienda digna y adecuada no sea relevante para la CE, pero su posición constitucional se reduce a ser un principio rector de la política social y económica de los poderes públicos (art. 53.3); su dimensión constitucional no es la de un derecho fundamental.

Casi al principio de este trabajo se suscitaba si hay derechos constitucionales no fundamentales. Para la teoría liberal sí, porque establece una clara diferencia entre éstos últimos que son los derechos que la Constitución reconoce, pero cuyo fundamento jurídico es meta-positivo, se considera que existen al margen y con anterioridad a la Constitución, y los derechos simplemente constitucionales, que son los que emanan de la Constitución y 
sin ella no tendrían existencia propia. Desde una perspectiva exclusivamente positivista, que considera la Constitución como norma jurídica suprema, puede afirmarse que en la Constitución española todos los derechos que en ella se reconocen o son derechos fundamentales o, como se acaba de ver en relación con el Capítulo III del Título I, son meros principios rectores aunque algunos se enuncien como derechos. Los derechos fundamentales son los recogidos en los Capítulos I y II en cuanto participan de las dos notas básicas del carácter fundamental de los derechos ya mencionadas, la disponibilidad del derecho por su titular y la indisponibilidad de su existencia por el legislador. En este sentido, la fundamentalidad de los derechos es una cuestión de grado; unos derechos son jurídicamente más fundamentales que otros en función de su mayor o menor preservación normativa a favor de su titular y frente al legislador.

Pudiera pensarse que fuera del Título I CE hay derechos constitucionales no fundamentales; por ejemplo, cuando se establece que una ley regulará la audiencia de los ciudadanos en el procedimiento de elaboración de las disposiciones administrativas que les afecten, o el acceso de los ciudadanos a los archivos y registros administrativos (art. I05, a y $b$, respectivamente), o la gratuidad de la justicia en caso de insuficiencia de recursos para litigar (art. II9), etc. Sin embargo, si se les considera «derechos constitucionales» habrá que estimar que la ley llamada a regularlos está concretando un «derecho fundamental», pues es un contrasentido admitir derechos constitucionales sobre cuya existencia pueda decidir el legislador. Y, si se acepta esta plena disponibilidad por el legislador, entonces los preceptos constitucionales que regulan dichas situaciones son semejantes a los que establecen los principios rectores de la política social y económica (Capítulo III del Título I CE).

Aunque sobrepasaría el espacio concedido estudiar con detalle la cláusula de garantía del contenido esencial de los derechos fundamentales (art. 53.I CE) no es posible concluir sin una referencia a ella, aunque sea somera, por cuanto es concreción de la fundamentalidad de los derechos fundamentales

Habitualmente esta garantía se estudia desde la perspectiva del ámbito de actuación del legislador en relación con los derechos fundamentales, lo cual es adecuado si se trata de examinar el contenido y límites de los derechos. Pero ello no puede hacer perder de vista que el contenido esencial de los derechos fundamentales como límite al legislador (art. 53.I CE) es una consecuencia de expresar tal garantía un poder de disposición que la Constitución reserva al titular del derecho sobre determinados ámbitos vitales, enunciados en abstracto, pero reconocibles en su núcleo y, por tanto, directamente ejercibles al menos en ese mínimo. Si se concibe la garantía del contenido esencial de los derechos fundamentales exclusivamente desde la perspectiva del límite a los límites que pueda establecer el legislador, el acento se pone en la Constitución entendida como fuente sobre las fuentes, o sea, como norma cuyo objeto es regular y delimitar el ámbito de la ley; el contenido esencial como campo no disponible por el legislador. Pero esta perspectiva no ayuda a explicar la fundamentalidad de los derechos y puede concluir en una obviedad: cualquier derecho subjetivo y cualquier norma -sea constitucional o no- tiene un contenido esencial (STC 11/1981 F.J. $1^{\circ}$ ) y el legislador no puede reducir a un mero nominalismo el contenido de los preceptos constitucionales. Por el hecho de estar recogido en la Constitución, «el tipo abstracto de un derecho (subjetivo) preexiste conceptualmente al momento legislativo» (STC 11/1981 F.J. $1^{\circ}$ ). De este modo, la cláusula del contenido esencial tan sólo haría explícito que también tienen carácter constitucional vinculante las normas que reconocen los derechos fundamentales. Pero implícitamente ese carácter lo tienen todas las normas constitucionales y por eso está obligado el legislador a respetarlas.

La garantía del contenido esencial de los derechos fundamentales cobra pleno sentido si se inserta en la concepción de la Constitución como norma jurídica suprema, como máxima fuente directa que confiere a las normas iusfundamentales la fuerza jurídica irresistible que es capaz de desplegar en el tiempo, en el espacio y en relación con cualquier 
materia y sujeto, y por tanto los articula con pretensión de eficacia inmediata y universal (o sea, frente a todos).

Sólo teniendo esto presente puede entenderse cabalmente la posición del legislador en relación con los derechos fundamentales y en qué sentido no puede disponer de ellos. Si la fundamentalidad de los derechos radicase en que son indisponibles por el legislador, no se podría explicar el papel que corresponde al legislador democrático en el desarrollo de los derechos fundamentales, ni los derechos fundamentales de configuración legal, ni la inconstitucionalidad por omisión.

Los derechos fundamentales no preexisten al ordenamiento constitucional, pero preexisten al legislador. Esto no significa que el legislador no pueda regularlos. El legislador de los derechos fundamentales no es un mero ejecutor de la Constitución; dada la formulación abstracta y lapidaria de los enunciados de las normas iusfundamentales, el legislador interviene en la concreción delimitadora del objeto y contenido de tales derechos y la Constitución le reserva un papel primordial. Sin embargo, la fuerza normativa de los derechos fundamentales y su pretensión de eficacia inmediata condicionan la posición y la actuación del legislador. Éste no puede desconocer ni los límites que la Constitución le marca ni ignorar que cuando es llamado a desarrollar el contenido de los derechos lo es con carácter imperativo, para dar efectividad a las normas iusfundamentales.

El contenido esencial de los derechos muestra su raíz cuando liga la fundamentalidad de los derechos a la fundamentalidad de la Constitución; por ejemplo, cuando, en ausencia de ley que dé efectividad al derecho fundamental, el contenido esencial de los derechos fundamentales se hace directamente presente. No funciona como límite al legislador ya que éste no ha actuado. Funciona como fuente constitucional directa de apoderamiento al titular del derecho para que pueda accionar preservando el ámbito de libertad garantizado. Así se consideró en la STC 15/1982, F.J. $8^{\circ}$ reconociendo eficacia directa del contenido mínimo del derecho a la objeción de conciencia al servicio militar, ante la inactividad del legislador, a pesar de que se trata de un derecho fundamental cuya regulación precisa de una previa intervención legislativa. Con mayor claridad aún se puede observar en la STC 31/1994 la función que cumple la garantía del contenido esencial de expresar la fundamentalidad de un derecho fundamental. La sentencia es interesante porque convierte lo que antes era considerado por el TC un derecho de rango legal en un derecho fundamental. En la STC I2/1982 se vio que para el TC el derecho a crear una emisora de televisión aunque podía ser una libertad instrumental incluida en el art. 20.I CE no era una derivación necesaria y el legislador podía decidir sobre su implantación o no. En cambio, la STC 31/I994, F.J. $7^{\circ}$, afirma que «sin negar la conveniencia de una legislación ordenadora del medio, en tanto ésta no se produzca, no cabe porque subsista la laguna legal sujetar a concesión o autorización administrativa -de imposible consecución, por lo demás- el ejercicio de la actividad de emisión de televisión local por cable, pues ello implica el desconocimiento total o supresión del derecho fundamental a la libertad de expresión y de comunicación que garantiza el art. 20.I a) y d)».

«Como ha señalado reiteradamente este Tribunal, los principios constitucionales y los derechos y libertades fundamentales vinculan a todos los Poderes Públicos (art. 9.I y 53.I C.E.) y son origen inmediato de derechos y obligaciones y no meros principios programáticos, no sufriendo este principio general de aplicabilidad inmediata más excepciones que las que imponga la propia Constitución expresamente o que la naturaleza misma de la norma impida considerarla inmediatamente aplicable (SSTC I5/1982, fundamento jurídico 9.; 254/i993, fundamento jurídico 6.). Cierto es que cuando se opera con la interpositio legislatoris es posible que el mandato constitucional no tenga, hasta que la regulación se produzca, más que un mínimo contenido que ha de verse desarrollado y completado por el legislador (SSTC I5/I982, fundamento jurídico 8.; 254/I993, 
fundamento jurídico 6.), pero de ahí no puede deducirse sin más que la libertad de comunicación ejercitada por las entidades demandantes de amparo no forma parte del contenido mínimo que consagra el art. 20.I a) y d) C.E» (STC 3I/1994 F.J. $7^{\circ}$ ).

La fundamentalidad de los derechos fundamentales, su participación en la esencia de la Constitución como norma suprema, soberana, se manifiesta también en la pretensión de eficacia extraterritorial.

«La responsabilidad de los órganos judiciales españoles por acción u omisión en los procedimientos de extradición no se limita a las consecuencias de su propia conducta. En la medida en que con dicho procedimiento se concreta un estrecho complejo de actuaciones imbricadas, en el país requirente y en el requerido, el destino del extraditado en aquél no es ni puede ser indiferente para las autoridades de éste. Por ello, se encuentran obligadas a prevenir la vulneración de derechos fundamentales, que les vinculan como bases objetivas de nuestro ordenamiento, incluso si esa vulneración se espera de autoridades extranjeras, atrayéndose la competencia de los Tribunales españoles por el dominio de que disponen sobre la situación personal del extraditado, y, por tanto, por los medios con que cuentan para remediar los efectos de las irregularidades denunciadas» (STC 13/1994 F.J. $4^{\circ}$ ).

Otra consecuencia de la fundamentalidad de los derechos fundamentales es la presunción de ilegitimidad de los límites que el legislador imponga a los derechos. La ley no sólo debe mostrar su habilitación para interponerse entre la Constitución y los titulares de los derechos. También ha de justificar, como sostiene reiterada jurisprudencia, que esos límites sean idóneos, necesarios y proporcionados.

Desde esta concepción de la fundamentalidad de los derechos fundamentales cobra sentido constitucional la calificación liberal de los derechos fundamentales como «inviolables e inalienables». Indica que portan aquella fuerza irresistible de la norma fundamental del ordenamiento que se convierte en una pretensión de eficacia directa y que les sitúa en una posición tal que su vulneración o su mero desconocimiento son antijurídicos, provengan de un poder público, incluido el legislador (eficacia vertical), o de sujetos privados (eficacia horizontal).

Así entendida la fundamentalidad de los derechos, puede decirse que los derechos fundamentales no son una categoría estanca, sino que unos derechos son más fundamentales que otros. La mayor o menor fundamentalidad dependerá de su mayor o menor grado de participación en la condición de la Constitución como norma fundamental del ordenamiento y fuente directa de relaciones jurídicas. Se supone que aquellos derechos que el sistema constitucional considere más esenciales para su identidad y funcionamiento los dotará de mayor fundamentalidad, o sea, les garantizará una efectividad más inmediata ya permitiendo un ejercicio directo de los mismos, ya vinculando estrechamente al legislador, obligándole a dictar la legislación que permita el ejercicio ordenado de los derechos y predeterminando su contenido. A la vez, los hará más inviolables, bien mediante garantías formales (reservas de ley reforzadas) y jurisdiccionales (recursos de amparo), bien mediante su exclusión de la posibilidad de ser suspendidos (art. 55) e incluso haciendo indisponibles esos derechos al poder de reforma constitucional (reforma agravada del art. I68 CE, en relación con el art. I67 CE), cláusulas de intangibilidad constitucional (art. 79.3 LFB). 